\title{
Down-regulation of Lsm I is involved in human prostate cancer progression
}

\section{S Takahashi*,', S Suzuki', S Inaguma', Y-M Cho', Y Ikeda', N Hayashi' ${ }^{2}$, T Inoue ${ }^{2}$, Y Sugimura ${ }^{2}$, N Nishiyama ${ }^{3}$, T Fujita $^{3}$, T Ushijima ${ }^{4}$ and T Shirai'}

'First Department of Pathology, Nagoya City University Medical School, I Kawasumi, Mizuho-cho, Mizuho-ku, Nagoya 467-860 I, Japan; ²Department of Urology, Aichi Cancer Center, I-I Kanokoden, Chikusa-ku, Nagoya 464-0021, Japan; ${ }^{3}$ Department of Urology, Nagoya Memorial Hospital, 4-305

Hirabari, Tenpaku-ku, Nagoya 468-8520, Japan; ${ }^{4}$ Carcinogenesis Division, National Cancer Center Research Institute, 5-I-I Tsukiji, Chuo-ku,

Tokyo 104-0045, Japan

Prostate cancer has become the most common malignancy in men in western countries (Pisani et al, 1993) and while the incidence and mortality from this cause in Japan are much lower, they appear to be rapidly increasing (Hsing et al, 2000). Androgen ablation therapy is generally accepted for prostate cancer. However, the outgrowth of androgen-independent cancer cells is a frequent outcome, eventually lead to the patient's death. Therefore, understanding of the molecular mechanisms of the acquisition of metastatic potential or the androgen-independent phenotype of tumour cells is urgently needed.

Several molecular cytogenetic studies have demonstrated that interstitial deletions of chromosomes $5 \mathrm{q}, 6 \mathrm{q}, 7 \mathrm{q}, 8 \mathrm{p}, 10 \mathrm{p}, 10 \mathrm{q}$, $13 \mathrm{q}, 16 \mathrm{q}, 17 \mathrm{p}, 17 \mathrm{q}$, and $18 \mathrm{q}$ are the most prevalent changes in human prostate cancers (Latil and Lidereau, 1998; Brothman et al, 1999; Verma et al, 1999; Ozen and Pathak, 2000), suggesting the presence of tumour suppressor genes in these regions. In particular, loss of heterozygosity $(\mathrm{LOH})$ at chromosome $8 \mathrm{p}$ has been found in a majority of prostate cancers.

We examined the genes differentially expressed in advanced prostate cancers using cDNA-representational difference analysis (RDA), which is an efficient and reliable technique to isolate genes differentially expressed between samples to be compared (Hubank and Schatz, 1994), and thereby isolated the Lsml gene as one of them. The Lsm1 gene was mapped to $8 \mathrm{p} 11.2$, a region which is

*Correspondence: S Takahashi; E-mail: sattak@med.nagoya-cu.ac.jp Received 16 August 200I; revised 17 December 200I; accepted 28 December 2001 frequently deleted in prostate cancers, using BLAST search program and down-regulation shown for refractory cancer and androgenindependent DU145 and PC3 cells. The data prompted the present examination of whether Lsm1 is a target gene involved in the acquisition of androgen-independence or the metastatic phenotype in human prostate cancers.

\section{MATERIALS AND METHODS}

\section{Samples}

Normal prostate and organ-confined prostate cancers were obtained from patients who underwent total cystoprostatectomy or prostatectomy for bladder or prostate cancer. None of these cancer patients had previously undergone chemotherapy, radiotherapy or hormonal therapy. Refractory prostate cancers were obtained from autopsy cases who died of the disease. All autopsy cases had undergone hormonal therapy using anti-androgens, $\mathrm{LH}-\mathrm{RH}$-agonist or castration. Human prostate cancer cell lines, DU145, LNCaP and PC3, were purchased from the American Type Culture Collection. For cDNA-RDA, localised prostate cancer (moderately differentiated adenocarcinoma, Gleason's score: $3+4=7$ ) and refractory cancer (poorly differentiated adenocarcinoma, Gleason's score: $5+5=10$ ) were used.

\section{CDNA-RDA}

cDNA was synthesised by using molony murine leukemia virus reverse transcriptase (Gibco - BRL) with oligo-d(T) primers. 
Subsequent RDA was essentially performed with minor modifications as previously described (Ushijima et al, 1997). Briefly, to prepare representations (amplicons), $5 \mu \mathrm{g}$ aliquots of double-stranded cDNA were digested with Sau3AI (Toyobo Biochemicals, Osaka, Japan), phenol extracted and ethanol precipitated, followed by ligation with $\mathrm{R}-\mathrm{Bgl}$ adaptor cassettes (RBgl-24: 5'-AGCACTCTCCAGCCTCTCACCGCA-3'; R-Bgl-12: 5'GATCT-GCGGTGA-3'). The ligation products were amplified using the R-Bgl-24 as the primer ( 25 cycles of 1 min each at $95^{\circ} \mathrm{C}$ and $3 \mathrm{~min}$ at $72^{\circ} \mathrm{C}$ ). Both tester and driver representations were digested with Sau3AI to remove the R-Bgl adaptors. The tester representations were then purified by gel filtration chromatography (cDNA spun column, Amersham Pharmacia Biotech) and then ligated to the J-Bgl adaptor (J-Bgl-24: $5^{\prime}$ ACCGACGTCGACTATCCATGAACA-3'; J-Bgl-12: 5'-GATCTGTTCATG-3'). Two hundred nanograms of J-adaptor-ligated tester DNA was mixed with $40 \mu \mathrm{g}$ of the driver DNA, hybridised for $21 \mathrm{~h}$ at $67^{\circ} \mathrm{C}$, and amplified by PCR with J-Bgl-24 as primer for 10 cycles. After digestion of single-stranded DNA with Mung-bean nuclease (New England Biolabs, Inc., Beverly, MA, USA), additional PCR amplification for 20-30 cycles with J-Bgl-24 was performed. The second competitive hybridization was performed by switching to the $\mathrm{N}-\mathrm{Bgl}$ adaptor (N-Bgl-24: 5'-AGGCAACTGTGCTATCCGAGGGAA-3'; N-Bgl-12: $5^{\prime}$-GATCTTCCCTCG-3'). One hundred nanograms of ligation solution were mixed with $20 \mu \mathrm{g}$ of driver DNA. Denaturing, reannealing, and selective amplification of the self-annealed product were performed as for the first cycle. The final PCR products which removed the adaptor were ligated into pBluescript II that had been digested with BamHI (Toyobo Biochemicals) and treated with calf intestinal alkaline phosphatase (Takara Biomedicals, Shiga, Japan). After transformation of XL1Blue-competent cells, insert-positive plasmid clones were selected by PCR amplification of the inserts using T3 and T7 primers and restriction-digestion of the PCR products with Sau3AI.

\section{Sequencing analysis}

DNA sequencing was performed on an ABI PRISM 310 Genetic Analyzer (Perkin Elmer Applied Biosystems) using a BigDye Terminator Cycle Sequencing FS Ready Reaction Kit (Perkin Elmer Applied Biosystems). Sequencing data were analysed with BLAST search program (http://www.ncbi.nih.gov/blast/blast.cgi) (Altschul et al, 1990).

\section{Northern blot analysis}

Total RNAs were isolated using RNAzol (Tel-test, Inc., TX, USA) and 10 microgram aliquots from prostate tissues were separated by electrophoresis in 1\% agarose-formaldehyde gel and transferred to nylon membranes (Hybond-N, Amersham Pharmacia Biotech, UK). RDA clones inserted into pBluescript II and a human glyceraldehyde-3-phosphate dehydrogenase (GAPDH) cDNA (Clontech, UK), employed as internal standard, were used as the probes. Expression signals were quantitatively analysed using a den-sitometer (ImageMaster, Amersham Pharmacia Biotech).

\section{DNA transfection}

A human Lsm1 cDNA fragment including full open reading frame was cloned into the pTarget mammalian expression vector (Pro-mega, WI, USA). DNA transfection into PC3 cells was carried out with a Lipofectin protocol (Life Technologies, Inc. MD, USA). Stable transfectants were selected with $500 \mu \mathrm{g} \mathrm{ml}^{-1} \mathrm{G} 418$ (Life Technologies, Inc.) and established by ring cloning.

\section{Cell proliferation assay}

PC3 and its transfectants were maintained in F-12K medium (Life Technologies, Inc.) containing $10 \%$ foetal bovine serum and incubated at $37^{\circ} \mathrm{C}$ under a humidified $5 \% \mathrm{CO}_{2}$ atmosphere. Cells were seeded into a 24 -well plate at a density of $1 \times 10^{4}$ cells per $2 \mathrm{ml}$ medium, and incubated for 3,5 and 7 days. Live cells from each culture were counted using Trypan blue staining. Each assay was carried out at least in triplicate.

\section{Chemoinvasion assay}

A membrane invasion culture system was used to measure tumour cell invasion (Albini et al, 1987; Hendrix et al, 1987). Sterile cell culture inserts with $8 \mu \mathrm{m}$ pore sized polyethylene terephthalate filters (Becton Dickinson, NJ, USA) were coated with $100 \mu \mathrm{g}$ basement membrane Matrigel (Becton Dickinson), dried under laminar flow hood, and placed in 24-well plates filled with F-12K medium containing $0.1 \%$ bovine serum albumin (BSA) and $10 \mu \mathrm{g} \mathrm{ml}^{-1}$ fibronectin as a chemoattractant. Cells $\left(1 \times 10^{5}\right)$, suspended in F$12 \mathrm{~K}$ containing $0.1 \% \mathrm{BSA}$, were seeded in cell culture inserts and, after incubation at $37^{\circ} \mathrm{C}$ for $24 \mathrm{~h}$, the filters were fixed in $80 \%$ ethanol and stained with Giemsa. Invaded cells were counted under microscope at high power fields. Each assay was carried out at least in quadruplicate.

\section{Animals}

Male KSN (nu/nu) nude mice, 5-weeks-old, were purchased from Japan SLC, Inc. (Shizuoka, Japan). The animals were maintained and treated in accordance with institutional guidelines and in compliance with national and institutional law and politics. Cells $\left(1 \times 10^{6}\right)$ were inoculated into the subcutaneous tissues in their flanks. Tumour volume was calculated from the formula: tumour volume $=(\text { width })^{2} \times$ length $/ 2$ (Osborne et al, 1985). Mice were killed at 20 weeks for histological assessment of invasion or metastases of tumour cells.

\section{mRNA in situ hybridisation}

A fragment of Lsm1 complementary DNA, corresponding to nucleotides 434 to 582 of Lsm1 cDNA (Salgado-Garrido et al, 1999), was cloned into the vector pGEM-T (Promega, Madison, WI, USA). Antisense and sense Lsm1 riboprobes were prepared using pGEM-T/Lsm1 as the template and a digoxigenin RNA labelling kit (Roche Diagnostics). After deparaffinisation, sections were treated with $3 \mu \mathrm{g} \mathrm{ml}^{-1}$ proteinase $\mathrm{K}$ for $20 \mathrm{~min}$ at $37^{\circ} \mathrm{C}$, and postfixed in $4 \%$ paraformaldehyde for $10 \mathrm{~min}$. The sections were then placed in hybridisation buffer containing digoxigenin-labelled antisense riboprobes for $16 \sim 18 \mathrm{~h}$ at $42^{\circ} \mathrm{C}$. After hybridisation, the sections were washed in $2 \times \mathrm{SSC} / 50 \%$ formamide for $30 \mathrm{~min}$ at $42^{\circ} \mathrm{C}$, then TNE buffer ( $10 \mathrm{mM}$ Tris- $\mathrm{HCl}$ ( $\mathrm{pH} 8.0$ ), $500 \mathrm{mM} \mathrm{NaCl}$, $1 \mathrm{mM}$ EDTA) for $10 \mathrm{~min}$ at $37^{\circ} \mathrm{C}$. Thereafter, the sections were treated with $10 \mu \mathrm{g} \mathrm{ml}^{-1}$ of RNase (Roche Diagnostics) for $30 \mathrm{~min}$ at $37^{\circ} \mathrm{C}$. The slides were rinsed in buffer A (100 mM maleic acid, $150 \mathrm{~mm} \mathrm{NaCl}, \mathrm{pH} 7.5$ ) for $10 \mathrm{~min}$, and then incubated with buffer C (1\% blocking reagent (Roche Diagnostics) dissolved in buffer A). Horse-radish peroxidase conjugated sheep anti-digoxigenin Fab fragments (1:100, Roche Diagnostics) were applied for $30 \mathrm{~min}$. The slides were then washed in buffer A followed by incubation with biotinylated tyramide in amplification diluent (NEN Life Science Products, Inc., Boston, MA, USA) for $10 \mathrm{~min}$, three times in buffer A for $5 \mathrm{~min}$ and alkaline phosphate conjugated streptoavidin (1:5000, Roche Diagnostics) for $30 \mathrm{~min}$. After sequential washing in buffer A containing $0.2 \%$ Tween 20 and buffer B (100 mM Tris- $\mathrm{HCl}$ (pH 9.5), $100 \mathrm{~mm} \mathrm{NaCl,} 50 \mathrm{~mm}$ $\mathrm{MgCl}_{2}$ ), hybridization signals were detected with 5-bromo-4chloro-3-indolyl-phosphate (BCIP)/4-nitro blue tetrazolium chlor- 
ide (NBT) solution (Roche Diagnostics). The specificity of the in situ hybridisation was proven by parallel hybridisation of the sections with sense riboprobes.

\section{LOH analysis}

LOH was examined by PCR amplification of highly polymorphic microsatellite repeat markers on chromosome 8p11.2, including D8S1747, D8S416 and D8S1722, around Lsm1 gene. The order of these loci has been determined by available human genome sequencing data for $8 \mathrm{p} 11.2$ of the Japan Science Technology Corporation (JST) (http://www-alis.tokyo.jst.go.jp/HGS/top.pl) to be: D8S1722-Lsm1 gene-D8S416-D8S1747. PCR reactions were performed with ${ }^{32} \mathrm{P}$-end-labelled primers for $35-45$ cycles at $94^{\circ} \mathrm{C}$ for $1 \mathrm{~min}, 56^{\circ} \mathrm{C}$ for $1 \mathrm{~min}$ and $72^{\circ} \mathrm{C}$ for $1 \mathrm{~min}$ in a $15 \mu \mathrm{l}$ volume. The PCR products were separated on $6 \%$ polyacrylamide sequencing gels and used to expose X-ray films. Allelic loss was judged when a reduction in signal intensity of $\leqslant 50 \%$ in one allele was evident in the tumour as compared to the paired normal tissue.

\section{Gene mutation analysis}

The region covering Lsm1 coding sequences was amplified by PCR in the presence of $\left[\alpha_{-}{ }^{32} \mathrm{P}\right] \mathrm{dCTP}$. The PCR products were then subjected to single-strand conformational polymorphism (SSCP) analysis under two conditions (with or without $5 \%$ glycerol). The primers used to PCR-SSCP analysis were as follows; $5^{\prime}$ GCTGTGCATTGCAGCATTAT- ${ }^{\prime}$ and $5^{\prime}$-CGGGAGGAGATAAACTA-3' for exon 1; 5'-AAGATTTTTTCCTCTCTCC-3' and 5'-GAGATGTCCATAAATTAATA-3' for exon 2; 5'-GGTTTTTCCCTATACACTT- $3^{\prime}$ and $5^{\prime}$-TACAGCAGCTTAATAGTTTTC-3' for exon 3; 5'-GAAGTTTTCAAACCTGTCTC-3' and 5'-CACTTTCAACTTCTCTGCTT-3' for forepart of exon 4; and 5'-AACAAAGGGTGGAACAGCA- $3^{\prime}$ and $5^{\prime}$-AAGAGCCAACAGCCTCT- $3^{\prime}$ for the hind part of exon 4.

\section{Statistical analyses}

Differences of the data for cell proliferation, chemoinvasion assay and tumour volume of nude mice was statistically assessed by an ANOVA test (Scheffe's analysis).

\section{RESULTS}

Eleven genes were identified to be specifically down-regulated in advanced prostate cancers by the cDNA-RDA method and all of these were identical to known genes listed as follows; LIM protein (GenBank Accession \#AF061258), cytoplasmic dynein light chain 1 (U32944), small subunit of calpain (X04106), acylamino acidreleasing enzyme (D38441), human X-box binding protein 1 (hXBP-1)(M31627), PRO1073 (AF113016), Lsm1 (AJ238094), 5aminoimidazole-4-carboxamide ribonucleotide formyltransferase/ inosine monophosphate cyclohydrolase (U37436), KIAA0088 gene (D42041), prostasin (L41351) and thyroid hormone-binding protein (J02783). On the other hand, all of seven genes up-regulated in advanced cancers were unknown.

Among these, Lsm1 mRNA expression was detected by Northern blot analysis in three of three normal prostates, four of four organ-confined prostate cancers and in LNCaP cells, while no signals were found for three cases of advanced prostate cancers, including primary sites and bone metastatic foci, as well as DU145 and PC3 cells (Figure 1). Lsm1 mRNA expression was detected in normal epithelial and adenocarcinoma cells in the human prostates by in situ hybridisation (Figure 2). Lsm1 mRNA expression levels in LNCaP cells did not alter with growth in medium lacking androgens (data not shown).
Four stable PC3/Lsm1-transfectants (\#14-1, \#14-3, \#15-1 and $\# 15-2)$ were established, which demonstrated no significant differences in morphology or cell proliferation in comparison with parent PC3 or PC3/mock-transfectants (Figures 3 and 4). In contrast, significant reduction of invasive potential of all Lsm1transfectants was observed in the Matrigel chemoinvasion assay (Figure 4). Dihydrotestosterone did not affect the growth of Lsm1-transfectants (data not shown).

Three out of four transfectants were able to form tumour masses in implantation sites of nude mice. The average time for tumour formation with the \#15-1 transfectant was about 17 weeks while with the other transfectants (\#14-1, \#15-2) it was about 5 weeks. There were no obvious differences in the tumour volumes of each cells. Lymph node metastasis was reduced in \#15-1 and \#15-2 (Table 1). The transfectant \#14-1 showed lymph node metastases (three out of five mice) and marked reduction of Lsm1 gene expression in these metastatic foci and the primary tumours (implantation site) on in situ hybridization. The finding suggested that Lsm1 expression ceased in the \#14-1 transfectant during the course of proliferation at the implantation site.

D8S1747 and D8S416 markers were demonstrable located 700 and $350 \mathrm{kbp}$, respectively, downstream of the Lsm1 gene, while D8S1722 was present $120 \mathrm{kbp}$ upstream of the gene. Almost all of the informative prostatectomised cases without neoadjuvant therapy showed allelic retention of D8S1747, D8S416 and D8S1722 loci, except for one lymph node metastatic focus (case \#M129), whereas refractory cancers frequently showed allelic loss of these marker loci (Figures 5 and 6).

The available nucleotide sequence information of the GenBank accession number AP000065 and the data from LA (long and accurate) - PCR analysis for the intron 1 sequence revealed that Lsm1 is formed of four coding exons and three intervening introns spanning an area of $13100 \mathrm{bp}$ of genomic sequence on chromosome 8p11.2. The intron/exon splice sites and their flanking sequences are in agreement with the consensus splicing signals (Iida, 1990).

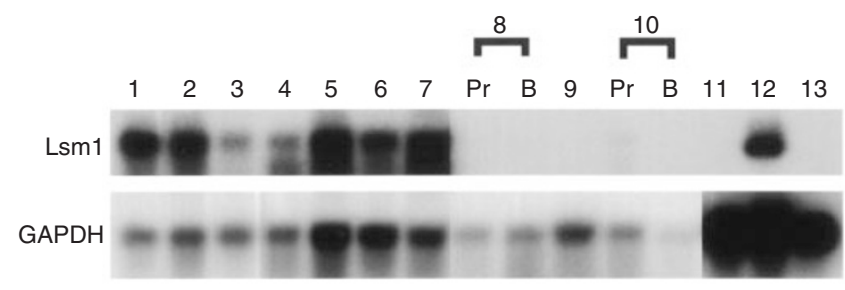

Figure I Northern blot analysis of human prostate total RNAs. Lanes I to 3, normal prostate tissues; lanes 4 to 7 , organ-confined cancers from prostatectomized cases; lanes 8 to 10, refractory cancers from autopsy cases, Pr: primary site, B: metastatic focus to the bone; lane II, DUI 45; lane 12, LNCaP; lane 13, PC3. Each lane was loaded with $10 \mu \mathrm{g}$ of total RNA.

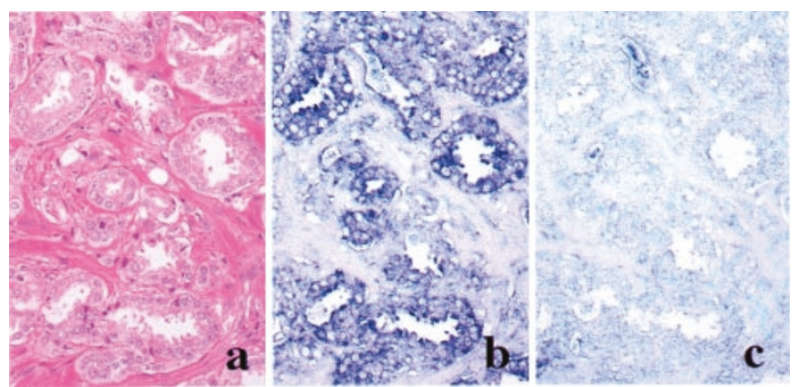

Figure $2 \mathrm{Lsm} / \mathrm{mRNA}$ expression in serial sections of a prostate adenocarcinoma. (a) H\&E. In situ hybridization with antisense (b) and sense (c) probes. 
No critical gene mutations were found in the open reading frame region of Lsm1 in 46 prostate cancer cases examined, including localized and refractory cases, by PCR-SSCP analysis.

\section{DISCUSSION}

Lsm1 was first isolated from human pancreatic cancers as an upregulated gene and termed cancer-associated Sm-like protein (Casm) (Schweinfest et al, 1997). Subsequently, Salgado-Garrido et al (1999) identified that Casm gene is identical to Lsm1 (like

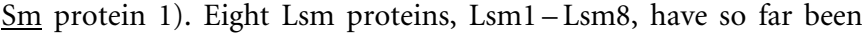
reported in humans (Achsel et al, 1999; Salgado-Garrido et al,
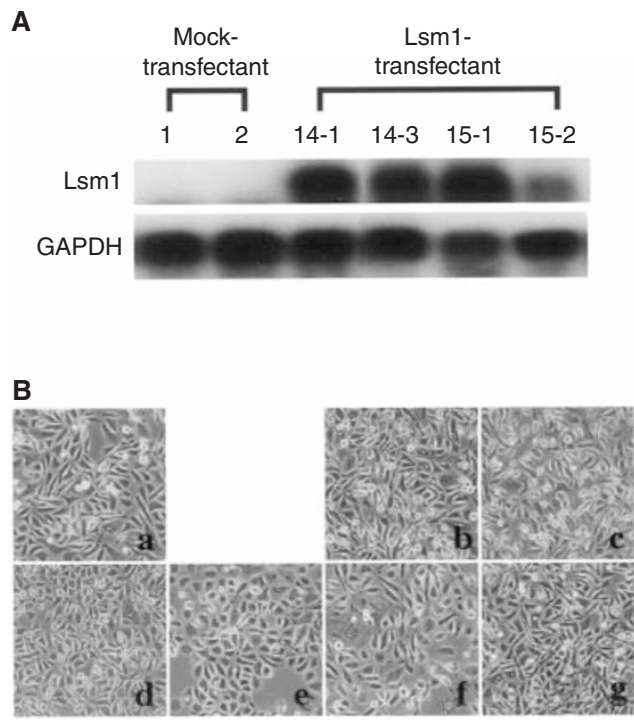

Figure 3 Establishment of $\mathrm{PC} 3 / \mathrm{Lsml}$-transfectants. (a) Total RNAs were extracted from PC3, mock and Lsml-transfectants and analysed for Lsm I levels by Northern blotting. (b) Morphology of PC3 and transfectant cells. PC3 (a), mockl (b), mock2 (c), Lsml//4-I (d), Lsml/I4-3 (e), LsmI/I5-I (f) and LsmI/I5-2 (g).

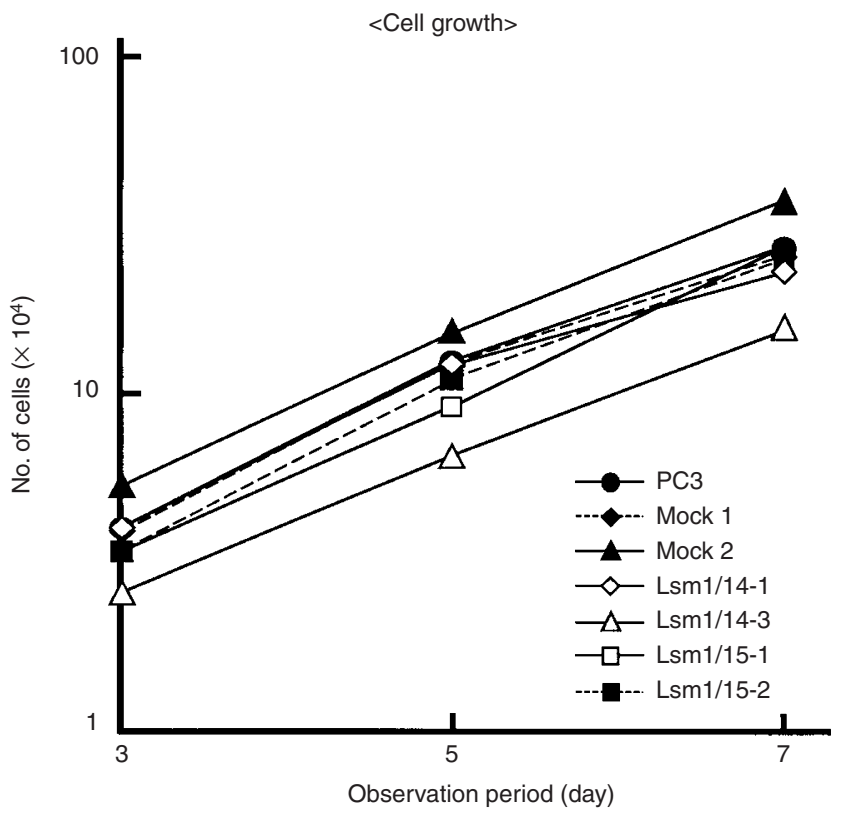

1999). Seven of these, Lsm 2 - Lsm8, have been shown to interact with U6 snRNA and facilitate formation of U4/U6 RNA duplexes (Achsel et al, 1999). Recent reports demonstrated that yeast Lsm 1 protein affects mRNA metabolism, particularly mRNA decapping and degradation (Boeck et al, 1998; Tharun et al, 2000) and it is possible that human Lsml regulates some specific genes related to tumour invasion or metastasis in prostate cancer cells. Further investigations are needed to clarify the molecular mechanisms of suppression of metastasis related to overexpression of the Lsm1 gene.

Although the number of samples was small and the quality of RNAs from refractory cancers due to sampling at autopsy was problematic, it is clear from the present transfection study that down-regulated expression of Lsm1 gene located at $8 \mathrm{p} 11.2$ is intimately involved in invasive and metastatic ability of human prostate cancers. The possible presence of putative tumour suppressor or metastasis suppressor genes in chromosome $8 \mathrm{p} 11.2$ in prostate cancers has been pointed out by several authors (Macoska et al, 1995; Crundwell et al, 1996; Prasad et al, 1998). Deletion of chromosome $8 \mathrm{p} 11.2$ has been frequently found in malignancies including stomach (Baffa et al, 2000), kidney (Schullerus et al, 1999), urinary bladder (Choi et al, 2000) and colorectal cancers (Chughtai et al, 1999), suggesting that Lsml gene is a candidate tumour suppressor or metastasis suppressor gene in common for a variety of human neoplasms.

The findings of a close association between down-regulation of Lsm1 and prostate cancer progression and the fact of abundant expression of Lsm1 in LNCaP but not in PC3 cells appear in conflict with the data reported by Schweinfest et al (1997). They also demonstrated diverse expression levels in many cancer cell lines. Regarding the two discrepancies, a possible cause of the former might be tissue-type specific Lsm1 expression. We have no explanation for the latter.

KAI1, a metastasis suppressor gene and a member of the membrane glycoprotein family, has been mapped to chromosome $11 \mathrm{p} 11.2$ and is known to contribute to metastasis of prostate cancer through down-regulation without gene mutations (Dong et al, 1995, 1996). Data on allelic loss of KAI1 region in prostate cancers are, however, conflicting, and it has been demonstrated that $\mathrm{LOH}$ is infrequent in American patients (Dong et al, 1996),

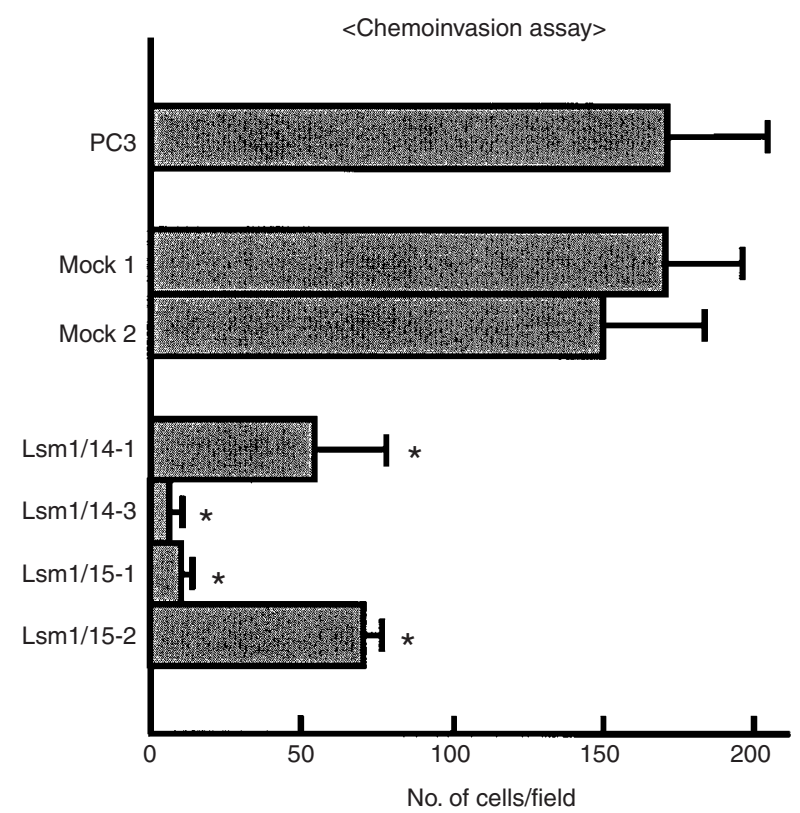

Figure 4 Data for cell growth and chemoinvasion assays of Lsm I-transfectants (means \pm s.d.). *Significantly different from the values for PC3, mock I or mock2 at $P<0.001$. 
Table I Characteristics of PC3/Lsm I-transfectants transplanted in nude mice

\begin{tabular}{|c|c|c|c|c|c|}
\hline \multirow[b]{2}{*}{ Cells } & \multirow{2}{*}{$\begin{array}{l}\text { No. of } \\
\text { mice }\end{array}$} & \multirow[b]{2}{*}{ Tumorigenicity } & \multirow{2}{*}{$\begin{array}{c}\text { Tumour volume } \\
\left(\mathrm{cm}^{3}\right)\end{array}$} & \multicolumn{2}{|c|}{ Metastasis/invasion } \\
\hline & & & & Lymph node & Vertebra \\
\hline PC3 & 9 & 9 & $4.19 \pm 3.06$ & 7 & 2 \\
\hline Mock I & 5 & 5 & $2.65 \pm 1.93$ & 5 & 0 \\
\hline Mock 2 & 5 & 5 & $4.54 \pm 2.90$ & 3 & 1 \\
\hline Lsml/|4-I & 5 & 5 & $5.51 \pm 2.28$ & 3 & 0 \\
\hline Lsm I//4-3 & 5 & 0 & - & 0 & 0 \\
\hline Lsml/|5-I & 5 & 4 & $0.57 \pm 0.78$ & 0 & 0 \\
\hline Lsm I/I5-2 & 5 & 5 & $3.56 \pm 2.27$ & 0 & 0 \\
\hline
\end{tabular}
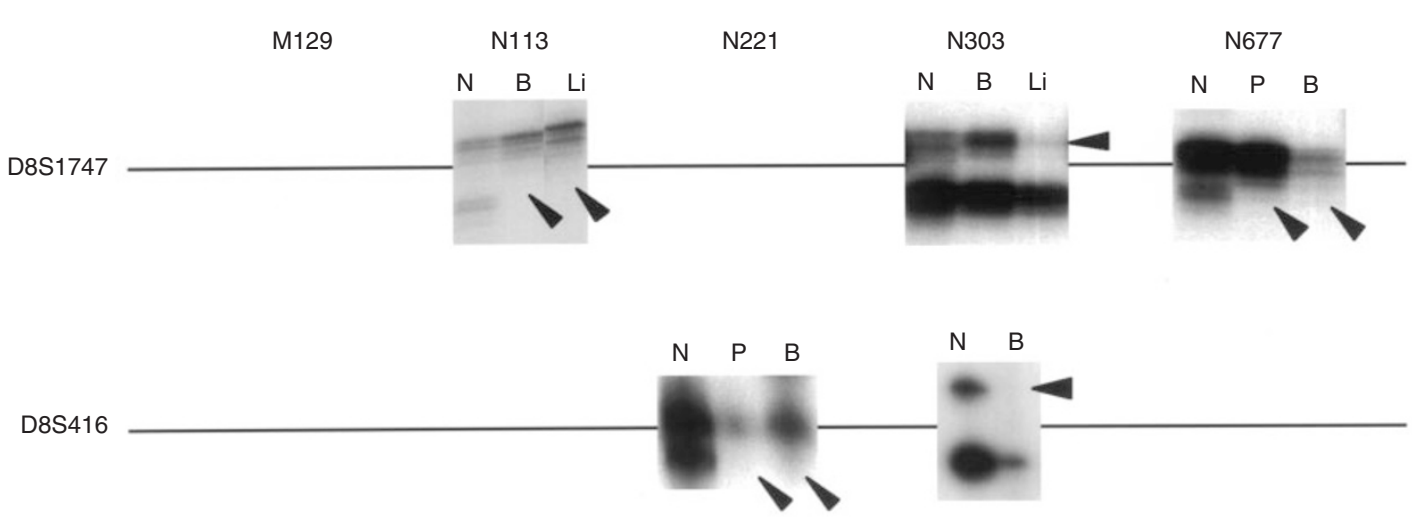

Figure 5 Autoradiograms illustrating the allelic losses on chromosome $8 \mathrm{p} \mid \mathrm{I} .2$ in prostate cancers. Arrowheads indicate allelic loss. The primer sequences used were 5'-CCACCTCTGATATGCCAATCAAG-3'/5'-TGGTTTCCTAAAACTTCACCCG-3' for D8SI747, 5'-GAGAATCGCTGGAACAGAGAAGG-3'/5'-GGCAGAGCTACCAAGAAACCAAAC-3' for D8S4I6 and 5'-CCTTGCTGGGAATTGTG-3'/5'-AGCTGCCTGGCTAAGAG-3' for D8SI722. N, normal tissues; P, primary site; LN, lymph node metastasis; B, bone metastasis; Li, liver metastasis.

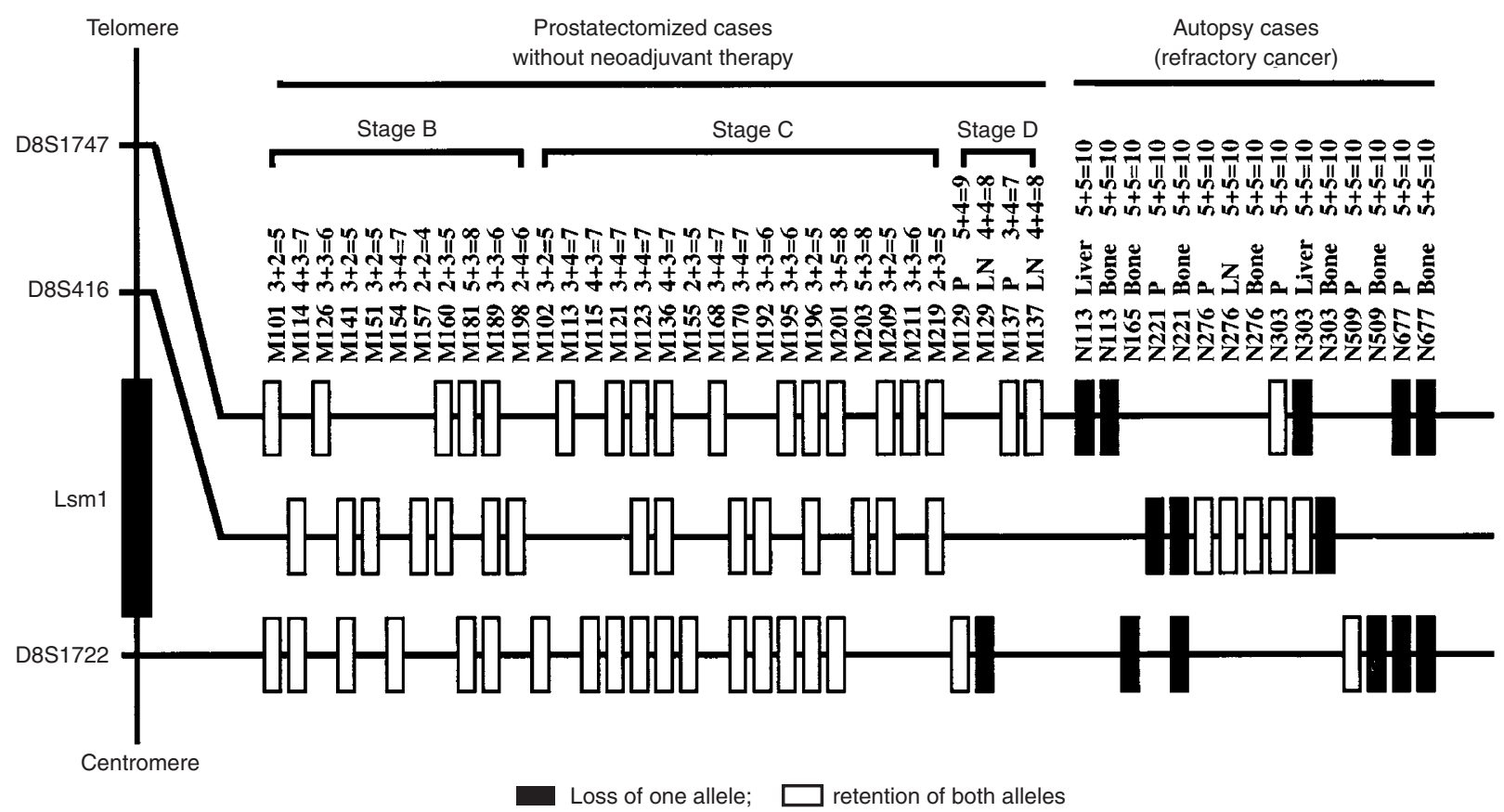

Figure 6 Summary of LOH for polymorphic markers surrounding the Lsm I gene on chromosome 8p I I.2 in a series of prostate cancers. P, primary site; LN, lymph node metastasis; Liver, liver metastasis; Bone, Bone metastasis. No mark indicates not informative. Numbers following the individual sample number represent their Gleason's score. 
while frequent in Japanese (Kawana et al, 1997). The standard form of CD44 is also a candidate metastasis suppressor gene located on chromosome $11 \mathrm{p} 13$, with potential involvement in prostate cancer progression through decreased expression (Gao et al, 1997). The present results demonstrated that Lsm1 suppressed prostate cancer metastasis through down-regulation, similar to the cases with the known metastasis suppressors, KAI1 or CD44, and we can speculate that the mechanism of decreased expression of this gene is reduction of gene dosage by allelic loss.

cDNA-RDA is a powerful and highly efficient method for identification of differentially expression of genes between two mRNA populations. However, it has limitations for enrichment of all differentially expressed genes during the procedure because of preferential amplification of some messages and the lack of Sau3A1 restriction sites in cDNAs. This might explain why genes known to be differentially expressed in advanced prostate cancer, such as KAI1 or CD44, were not isolated in the present study.

As shown in Figure 1, Lsml was here found to be expressed in LNCaP cells but not in PC3 and DU145 cells. These results suggest that Lsm1 expression may contribute to acquisition of the androgen-independent phenotype during prostate cancer progression. The lack of androgen receptors is the major cause of androgenindependency in PC3 and DU145 cells, with two factors thought to contribute the loss of androgen receptor expression; methylation of androgen receptor promoter and relative deficiency of transcrip-

\section{REFERENCES}

Achsel T, Brahms H, Kastner B, Bachi A, Wilm M, Luhrmann R (1999) A doughnut-shaped heteromer of human Sm-like proteins binds to the $3^{\prime}$ end of U6 snRNA, thereby facilitating U4/U6 duplex formation in vitro. EMBO J 18: $5789-5802$

Albini A, Iwamoto Y, Kleinman HK, Martin GR, Aaronson SA, Kozlowski JM, McEwan RN (1987) A rapid in vitro assay for quantitating the invasive potential of tumor cells. Cancer Res 47: 3239-3245

Altschul SF, Gish W, Miller W, Myers EW, Lipman DJ (1990) Basic local alignment search tool. J Mol Biol 215: 403-410

Baffa R, Santoro R, Bullrich F, Mandes B, Ishii H, Croce CM (2000) Definition and refinement of chromosome $8 p$ regions of loss of heterozygosity in gastric cancer. Clin Cancer Res 6: 1372-1377

Boeck R, Lapeyre B, Brown CE, Sachs AB (1998) Capped mRNA degradation intermediates accumulate in the yeast spb8-2 mutant. Mol Cell Biol 18: $5062-5072$

Brothman AR, Maxwell TM, Cui J, Deubler DA, Zhu XL (1999) Chromosomal clues to the development of prostate tumors. Prostate 38: 303-312

Chlenski A, Nakashiro K, Ketels KV, Korovaitseva GI, Oyasu R (2001) Androgen receptor expression in androgen-independent prostate cancer cell lines. Prostate 47: 66-75

Choi C, Kim MH, Juhng SW, Oh BR (2000) Loss of heterozygosity at chromosome segments 8 p22 and 8p11.2-21.1 in transitional-cell carcinoma of the urinary bladder. Int J Cancer 86: $501-505$

Chughtai SA, Crundwell MC, Cruickshank NR, Affie E, Armstrong S, Knowles MA, Takle LA, Kuo M, Khan N, Phillips SM, Neoptolemos JP, Morton DG (1999) Two novel regions of interstitial deletion on chromosome 8p in colorectal cancer. Oncogene 18: 657-665

Crundwell MC, Chughtai S, Knowles M, Takle L, Luscombe M, Neoptolemos JP, Morton DG, Phillips SMA (1996) Allelic loss on chromosomes 8p, 22q and $18 \mathrm{q}(D C C)$ in human prostate cancer. Int J Cancer (Pred Oncol) 69: $295-300$

Dong J-T, Lamb PW, Rinker-Schaeffer CW, Vukanovic J, Ichikawa T, Isaacs JT, Barrett JC (1995) KAI1, a metastasis suppressor gene for prostate cancer on human chromosome 11p11.2. Science 268: 884-886

Dong J-T, Suzuki H, Pin SS, Bova GS, Schalken JA, Isaacs WB, Barrett JC, Isaacs JT (1996) Down-regulation of the KAI1 metastasis suppressor gene during the progression of human prostatic cancer infrequently involves gene mutation or allelic loss. Cancer Res 56: 4387-4390

Gao AC, Lou W, Dong J-T, Isaacs JT (1997) CD44 is a metastasis suppressor gene for prostatic cancer located on human chromosome 11p13. Cancer Res 57: $846-849$ tion factors (Chlenski et al, 2001). As described above, Lsm1 might be involved in regulating some transcription factors related to androgen receptor expression but it may not interfere with the control of methylation levels in the promoter region. Hence it may be that overexpression of Lsm1 alone was not able to render PC3 cell androgen-dependent. The finding of high expression in LNCaP cells, which are derived from a lymph node metastasis, appears to contradict the conclusion of Lsm1 being a metastasis suppressor gene. However, an explanation for this may lie with alteration of the genes which are regulated by Lsm1. In fact, several genes have been identified to fluctuate with overexpression of Lsm1 using cDNA expression arrays (data not shown). Therefore, clarification of the signalling cascade regulated by Lsm1 may contribute to elucidation of the molecular mechanisms responsible for acquisition of metastatic ability in human prostate cancers.

\section{ACKNOWLEDGEMENTS}

This work was supported in part by a Grant-in-aid for cancer research from the Ministry of Health, Labour and Welfare of Japan, and a grant from the Society for Promotion of Toxicological Pathology in Nagoya, Japan.

Hendrix MJC, Seftor EA, Seftor REB, Fidler IJ (1987) A simple quantitative assay for studying the invasive potential of high and low human metastatic variants. Cancer Lett 38: $137-147$

Hsing AW, Tsao L, Devesa SS (2000) International trends and patterns of prostate cancer incidence and mortality. Int J Cancer (Pred Oncol) 85: $60-67$

Hubank M, Schatz DG (1994) Identifying differences in mRNA expression by representational difference analysis of cDNA. Nucleic Acids Res 22: $5640-$ 5648

Iida Y (1990) Quantification analysis of $5^{\prime}$-splice signal sequences in mRNA precursors. Mutations in $5^{\prime}$-splice signal sequence of human beta-globin gene and beta-thalassemia. J Theor Biol 145: 523-533

Kawana Y, Komiya A, Ueda T, Nihei N, Kuramochi H, Suzuki H, Yatani R, Imai T, Dong J-T, Imai T, Yoshie O, Barrett JC, Isaacs JT, Shimazaki J, Ito H, Ichikawa T (1997) Location of KAIl on the short arm of human chromosome 11 and frequency of allelic loss in advanced human prostate cancer. Prostate 32: $205-213$

Latil A, Lidereau R (1998) Genetic aspects of prostate cancer. Virchow Arch 432: $389-406$

Macoska JA, Trybus TM, Benson PD, Sakr WA, Grignon DJ, Wojno KD, Pietruk T, Powell IJ (1995) Evidence for three tumor suppressor gene loci on chromosome 8p in human prostate cancer. Cancer Res 55: 5390-5395

Osborne CK, Hobbs K, Clark GM (1985) Effect of estrogen and antiestrogens on growth of human breast cancer cells in athymic nude mice. Cancer Res 45: $584-590$

Ozen M, Pathak S (2000) Genetic alterations in human prostate cancer: a review of current literature. Anticancer Res 20: 1905-1912

Pisani P, Parkin DM, Ferlay J (1993) Estimates of the worldwide mortality from eighteen major cancers in 1985. Implications for prevention and projections of future burden. Int J Cancer 55: 891-903

Prasad MA, Trybus TM, Wojno KJ, Macoska JA (1998) Homozygous and frequent deletion of proximal $8 \mathrm{p}$ sequences in human prostate cancers: identification of a potential tumor suppressor gene site. Gene Chrom Cancer 23: $255-262$

Salgado-Garrido J, Bragado-Nilsson E, Kandels-Lewis S, Seraphin B (1999) $\mathrm{Sm}$ and Sm-like proteins assemble in two related complexes of deep evolutionary origin. EMBO J 18: $3451-3462$

Schullerus D, von Knobloch R, Chudek J, Herbers J, Kovacs G (1999) Microsatellite analysis reveals deletion of a large region at chromosome $8 \mathrm{p}$ in conventional renal cell carcinoma. Int J Cancer 80: $22-24$ 
Schweinfest CW, Graber MW, Chapman JM, Papas TS, Baron PL, Watson DK (1997) CaSm: An Sm-like protein that contributes to the transformed state in cancer cells. Cancer Res 57: $2961-2965$

Tharun S, He W, Mayes AE, Lennertz P, Beggs JD, Parker R (2000) Yeast Smlike proteins function in mRNA decapping and decay. Nature 404: 515518

Ushijima T, Morimura K, Hosoya Y, Okonogi H, Tatematsu M, Sugimura T, Nagao M (1997) Establishment of methylation-sensitive-representational difference analysis and isolation of hypo- and hypermethylated genomic fragments in mouse liver tumors. Proc Natl Acad Sci USA 94: 2284-2289 Verma RS, Manikal M, Conte RA, Godec CJ (1999) Chromosomal basis of adenocarcinoma of the prostate. Cancer Invest 17: $441-447$ 